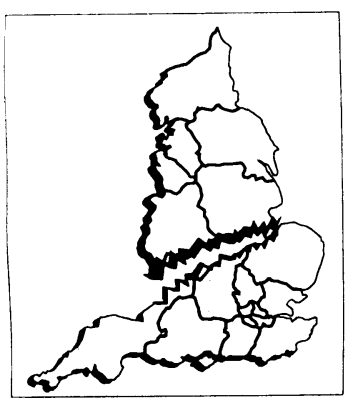

\title{
Strategy for asthma
}

\author{
P G J Burney
}

The government's consultative document The Health of the Nation marks a clear change in focus for the Department of Health ${ }^{1}$ away from the day to day issues of health service management towards a more active role in broader public health issues. Among its objectives it lists the reduction in deaths and ill health attributable to asthma, firstly, by the effective provision of health services and, in the long term, by establishing the aetiology of the disease.

\section{Why asthma should be a key area}

Asthma poses a major challenge to public health. Not only is it one of the commonest causes of chronic il health but it is also an increasing problem. In childhood, asthma is the commonest cause of losing time from school ${ }^{2}$ and has become one of the commonest causes of admission to hospital. ${ }^{3}$ Information on exactly how much asthma restricts adults' activity is less easy to determine. The Department of Health estimates that among the working population seven million working days were lost because of asthma in 1987-8. ${ }^{1}$

Rates of admission to hospital, ${ }^{4}$ prescribing, ${ }^{5}$ and consultation in general practice ${ }^{6}$ are all rising, and the evidence suggests that the prevalence of asthma is also increasing, at least among children. ${ }^{78}$ These increases, which are probably due to an increasing incidence, are not confined to the United Kingdom but have been widely reported around the world. Mortality from asthma also rose in the late 1970s and early 1980s and has not declined since. ${ }^{9}$ Whether this increase in mortality represents an increase in case fatality or simply reflects the change in prevalence is difficult to judge from the information available. However, it is likely that at least some of the increase is attributable to the growing prevalence. ${ }^{10}$

On the current evidence asthma is a preventable disease. The rapid increase and wide variation in prevalence and the changes in prevalence noted among migrants suggest an environmental component in the aetiology of asthma, which should be reversible. If the adverse changes that have been noted are largely the result of a changing incidence, logic dictates that the thrust of any health strategy should be towards primary prevention of the disease.

It is also likely that asthma could be better managed. There are now effective drugs for managing asthma, including both anti-inflammatory drugs and bronchodilators. There are also agreed guidelines for the management of asthma in children ${ }^{11}$ and in adults, both for long term treatment ${ }^{12}$ and for acute exacerbations. ${ }^{13}$ These guidelines are not yet widely followed, and shortcomings in the management of asthma have been reported to be associated with deaths from asthma,${ }^{14}$ patients admitted to hospital with asthma, ${ }^{15}$ and children missing school because of asthma. ${ }^{16}$

Health Medicine, United

Medical and Dental

Schools of Guy's and

St Thomas's Hospitals,

St Thomas's Campus, London SE1 7EH P G J Burney, FFPHM, reader in public health medicine

\section{Case against}

It is easy to argue that a reduction in morbidity from asthma should be a principal objective of government policy, but the case for setting targets is more difficult to argue and depends on how the targets are to be used.

\section{Government's possible targets for asthma}

- There are several difficulties in setting targetsfirstly, the identification of the targets themselves, and, secondly, their quantification. Simple targets related to reductions in mortality will be difficult to set because the factors which lead to death are not sufficiently well understood. Targets should therefore concentrate initially on reducing the amount of avoidable ill health

- It may be best to develop targets for defined populations based on adherence to published clinical management guidelines, the establishment of agreed protocols between general practitioners and hospital clinicians, the development of district wide strategies, etc. Monitoring the uptake of peak flow meters on prescription and the development of self management plans may also offer some scope for developing targets

- Work will be necessary to establish the link between such measures and health outcome. Consultation between the government, the NHS, and other interested parties will be necessary to develop suitable targets

The Health of the Nation is not clear on this point.' If targets are set simply to give direction to a programme of work and to allow progress to be monitored they do not pose great problems. If, on the other hand, they are to be used more specifically to set incentives, as with the recent changes to the general practitioners' contract, they would raise much greater difficulties.

Firstly, there is a problem with the case definition of asthma. Where specific surveillance systems can be set up this may not be an issue as standardisation and consistency are more important than adherence to some as yet undefined gold standard. Prevalence has thus been monitored over the past 18 years in English primary schools by the national study of health and growth ${ }^{8}$ and as the condition is common it would be possible to include similar questions in other national surveillance programmes. But surveillance based on diagnosed asthma, particularly in general practice where labelling might be variable, is unlikely to be useful. Targets such as the proportion of asthmatic patients with peak flow meters or with agreed management plans would be strongly influenced by the level of diagnosis.

A second problem arises when setting targets relating to aspects of care about which some of the evidence is now controversial. The current debate over the use of inhaled $\beta$ agonists is the most obvious example, ${ }^{17}$ but this is not the only contentious issue. Inhaled steroids are now suspected of producing more systemic side effects than was previously believed, ${ }^{18}{ }^{19}$ and many of the procedures that are thought to be self evidently good remain unproved in practice. For instance, much of the evidence in England on the effects of health education ${ }^{20}$ or self management ${ }^{2122}$ is unclear. Studies of self management have either been uncontrolled ${ }^{21}$ or have shown no significant difference between active and control treatments. ${ }^{22}$ In a condition such as asthma, which has a very variable course, this must lead to some reservations concerning the efficacy of these methods of controlling it, at least as tested. 
Reducing deaths and ill health attributable to asthma is a key government objective

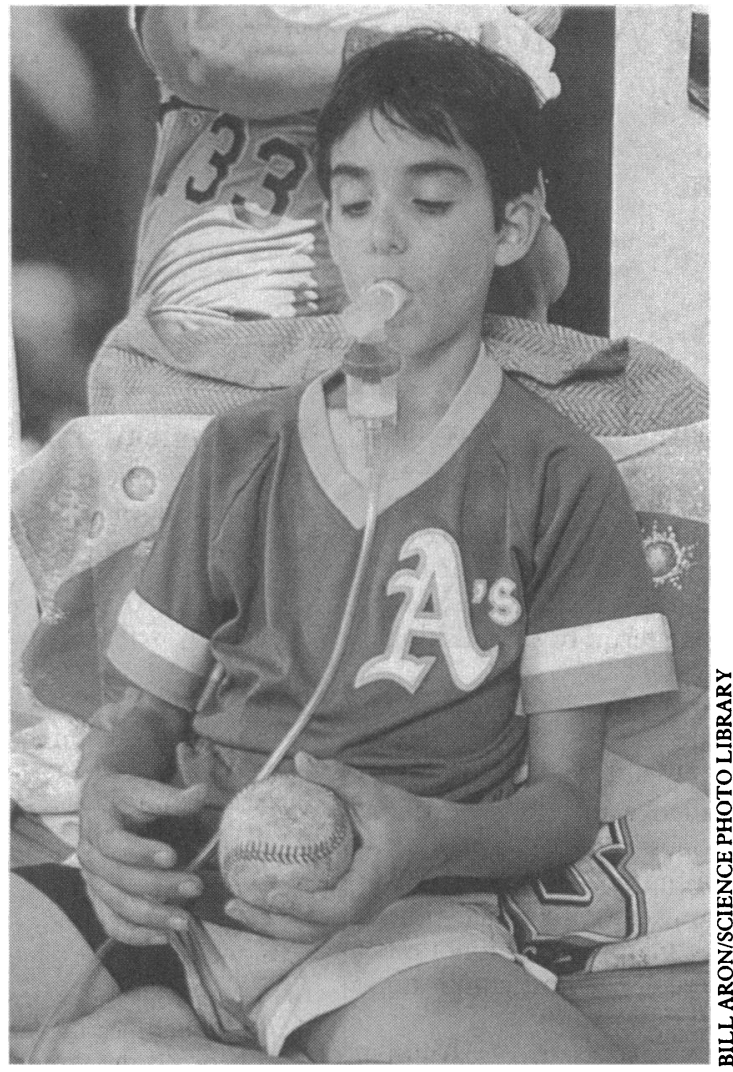

These reservations should not be overinterpreted. There is at least evidence that respiratory physicians do better than general physicians in managing asthma. ${ }^{2324}$ This implies that current specialist practice has important advantages and supports the view that abandoning current methods of management is likely to have worse consequences than continuing their use. ${ }^{25}$ Secondly, evidence on health education from the United States is more ambivalent, and some studies suggest that intensive programmes may be effective in reducing the numbers of emergency room visits ${ }^{26}$ or hospital readmissions. ${ }^{27}$ Whether this is due to a different message in the American health education, differences in the patients, or a difference in the medical environment is not clear. However, though some encouragement can be gained from these findings, they are not yet adequate to sustain specific claims for large amounts of resources or strong incentives for individual aspects of management.

\section{The targets}

As the principal problem with asthma is its increasing prevalence it is rational to set this as the main target to be monitored. Prevalence is currently monitored in primary school children, ${ }^{8}$ and monitoring could be extended to other national surveys without much difficulty. Monitoring the loss of quality of life due to asthma could also provide evidence on the overall effectiveness of the health services. As asthma is common it is reasonable to believe that monitoring would be informative within the likely sample size of any national programme. It might also be possible to monitor absence from school due to asthma, though case definition would be a problem and surveillance would add another administrative burden to a hard pressed education service.

Potential targets that are already measured routinely are difficult to identify. Mortality should be a target but death from asthma is rare and short term changes in death rates are unreliable. Rates of admission to hospital are hard to interpret: high rates may indicate both inadequate control of the disease in the community and an appropriate response to uncontrolled disease. Incentives to reduce hospital admissions could have perverse effects if this were not taken into account and if appropriate referrals to hospital were discouraged. Intermediate targets could be set by assessing adherence to the current guidelines on the management of asthma. Use of these guidelines is currently limited by uncertainty over management and by difficulty, at least in general practice, over case definition.

\section{Achieving the objective}

Three things are essential if the current trends are to be reversed. Firstly, we need to understand why the prevalence of asthma is increasing. There are now several clues suggesting possible reasons, but a coordinated research programme is required to test these rigorously and develop a preventive strategy for asthma. All the evidence strongly suggests that asthma is predominantly an environmental disease and that the current trends could be reversed. If current trends in mortality, admission to hospital, consultations, and prescribing are largely determined by changes in prevalence then primary prevention is the only credible long term strategy for dealing with the underlying problem.

Secondly, a further programme of research is required into the effectiveness and safety of different methods of managing asthma. It would be naive to assume that a treatment regimen free of side effects is available, but recent controversies have shown up several weaknesses in the scientific basis for the current management of asthma. We need to know more about both the long term effects of treatment and the other factors that influence the adequate control of asthma. Even if all the current anxieties are shown to be without foundation the current uncertainty alone could reduce the number of people getting adequate treatment. Moreover, it will remain difficult to insist on a particular form of management without clear evidence that it is both effective and efficient.

In the meantime it is important that current guidelines ${ }^{11-13}$ should be widely known and adhered to. They remain the best opinion that we have on the optimal management of asthma and such circumstantial evidence as we have suggests that patients treated according to these guidelines are likely to do better than those who are treated otherwise. Adherence to guidelines is probably best achieved through the organisation of local audit of asthma care.

Finally, it is necessary to inform the public more fully about what they should expect. Low expectations are probably as much a barrier to good management of asthma as any single defect in the health services.

\section{Expected problems}

The Health of the Nation indicates a change of emphasis towards more strategic issues.' Ironically, the section on asthma reverses this emphasis and focuses on managing the health services' response. Though there is clearly room for improvement in the way that asthma is managed, this reversal is unfortunate. If the principal problem is an increase in the prevalence and severity of asthma then this is the issue that should be addressed.

One problem with accepting a reduction in the prevalence and severity of asthma as a principal objective is that achieving it depends on a successful programme of research. While there is every prospect of this research being successful in the next few years such success cannot be taken for granted. Moreover, successful research is only the first requirement. Just as important is the application of the results of that research to an integrated programme for the preven- 
tion of asthma. For this to be successful it is important that the Department of Health should play an active part. Over the past decade almost all the initiatives have come from charities such as the National Asthma Campaign and professional bodies such as the British Thoracic Society. The greatest barrier to achieving a lower prevalence of asthma would be the Department of Health failing to live up to the promise of The Health of the Nation and reverting to the view that only those problems that have simple managerial solutions are of relevance to its strategy.

1 Secretary of State for Health. The Health of the Nation. London: HMSO, 1991. Cm 1523.)

2 Nocon A. Social and emotional impact of childhood asthma. Arch Dis Child 1991;66:458-60.

3 Hill AM. Trends in paediatric medical admissions. BMF 1989;298:1479-83.

Alderson M. Trends in morbidity and mortality from asthma. Population Trends 1987;49:18-23.

Hay I, Higginbottam T. Has the management of asthma improved? Lancet 1987; ; :609-11.

6 Fleming DM, Crombie DL. Prevalence of asthma and hay fever in England and Wales. BMf 1987;294:279-83.

Burr ML, Butland BK, King S, Vaughan-Williams E. Changes in asthma prevalence: two surveys 15 years apart. Arch Dis Child 1989;64:1452-6.

8 Burney PGJ, Chinn S, Rona R. Has the prevalence of asthma increased in children? Evidence from the National Study of Health and Growth 1973-86. BMF 1990;300:1306-10.

9 Burnev PGJ. Asthma mortality in England and Wales: evidence for a further increase 1974-1984.

10 Burney PGJ. Asthma deaths in England and Wales 1931-1985. evidence for true increase in asthma mortality. $\mathcal{F}$ Epidemiol Community Health 1988;42: truc increas

11 Warner JO, Götz M, Landon LI, Levison H, Milner AD, Pedersen S, et al.
Management of asthma: a consensus statement. Arch Dis Chlld 1984;04:

12 British Thoracic Society, Research Unit of Royal College of Physicians of London, King's Fund Centre, National Asthma Campaign. Guidelines for management of asthma in adults: I. Chronic persistent asthma. $B M \mathcal{J}$ 1990;301:651-3.

13 British Thoracic Society, Research Unit of Royal College of Physicians of London, King's Fund Centre, National Asthma Campaign. Guidelines for management of asthma in adults: II. Acute severe asthma. BMF 1990;301 797-800.

14 Johnson A, Nunn A, Somner A, Stableforth D, Stewart C. Circumstances of death from asthma. BMF 1984;288:1870-2.

15 Blainey D, Lomas D, Beale A, Partridge $M$. The cost of acute asthma-how much is preventable? Health Trends 1991;22:151-3.

16 Hill RA, Standen PJ, Tattersfield AE. Asthma, wheezing and school absence in primary schools. Arch Dis Child 1989;64:246-51.

17 Sears MR, Taylor DR, Print CG, Lake DC, Quinquing Li, Flannery EM, et al. Regular inhaled $\beta$ agonist treatment in bronchial asthma. Lancet 1990;336: $1391-6$.

18 Ali NJ, Capewell S, Ward MJ. Bone turnover during high dose inhaled corticosteroid treatment. Thorax 1991:46:160-4.

19 Wolthers OD, Pedersen S. Growth of asthmatic children during treatment with budesonide: a double blind trial. BMF 1991;303:163-5.

20 Hilton S, Sibbald S, Anderson HR, Freeling P. Controlled evaluation of the effects of patient education on asthma morbidity in general practice. Lancel 1986;i:26-9.

21 Beasley R, Cushley M, Holgate ST. A self-management plan in the treatmen of adult asthma. Thorax 1989;44:200-4.

22 Charlton I, Charlton G, Bloomfield J, Mullee MA. Evaluation of peak flow and symptoms only self-management plans for control of asthma in general practice. BMF 1990;301:1355-9.

23 Bucknall CE, Robertson C, Moran F, Stevenson RD. Differences in hospital asthma management. Lancet 1988; ; $748-50$.

24 Bucknall CE, Robertson C, Moran F, Stevenson RD. Management of asthma in hospital: a prospective audit. $B M \mathcal{F} 1988 ; 296: 1637-9$.

25 Rees PJ. $\beta_{2}$ agonists and asthma. $B M \mathcal{J}$ 1991;302:1166-7.

26 Maiman LA, Green LW, Gibson G, MacKenzie EJ. Education for selftreatment by adult asthmatics. FAMA 1979;241:1919-22.

27 Mayo PH, Richman J, Harris HW. Results of a program to reduce admission for adult asthma. Ann Intern Med 1990;112:864-71.

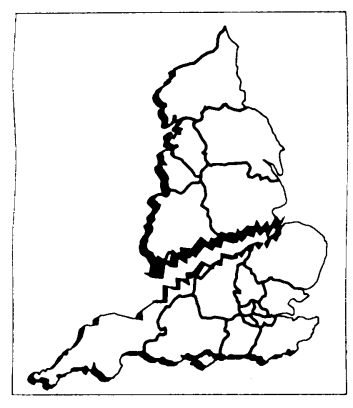

Academic Department of Genitourinary Medicine, University College and Middlesex School of Medicine, London WIN 8AA

Anne M Johnson, MFCM, senior lecturer in epidemiology

BMF 1991;303:573-6

\section{HIV and AIDS}

\section{Anne M Johnson}

The Health of the Nation described HIV and AIDS as "the greatest new threat to public health this century." Paradoxically, this major area of concern missed the status of a key area on the basis that insufficient prevalence data are currently available to set targets. This is a serious omission for an epidemic which will be most effectively contained by action taken early in its course.

In the emerging culture of management by objectives, managers will increasingly focus on achieving targets set nationally as well as locally through purchaser-provider contracts. The logical outcome is that areas in which targets have not been set will receive both insufficient effort and insufficient resources. Can we therefore afford not to set targets for a pandemic whose aetiology is well understood and for which a clear objective of improvement in safe sexual and injecting drug using behaviours can be set, even if realistic targets for the incidence of disease cannot? This immediately raises a well worn criticism of target setting; that priority is given to only those problems which are measurable. ${ }^{2}$ Damage limitation for AIDS and HIV requires early behavioural intervention, and target setting therefore cannot depend solely on the results of unlinked anonymous surveillance of serostatus, which may require data for several further years before clear trends emerge. ${ }^{3}$ This leads to a discussion of what constitutes a target.

In The Health of the Nation the targets are a mixture of measures of outcome (quantifiable measures of disease incidence and behavioural risk factors) and process measurements (concerned only with health service provision and policy). By contrast, the United States national health objectives, which were produced 10 years before the British strategy, took a broader perspective, identifying objectives in five areas: improving health status; reduced risk factors, increased

\section{Government's view on setting targets}

An essential first step is to improve understanding of the prevalence of HIV. This knowledge will assist service planning and targeting of public information campaigns. At present the information is insufficient to allow targets to be set for limiting the spread of HIV. The Medical Research Council, funded by the Department of Health, began anonymised surveys of serostatus in January 1990. As these studies become more generalised their results should enable more accurate predictors of the state and geographic distribution of the epidemic.

public and professional awareness; improved services and protection; and improved surveillance and evaluation systems. ${ }^{4.7}$ For HIV and AIDS the government considers only measures of health status, concluding that without better estimates of the current magnitude of the epidemic targets cannot be set (box). The Faculty of Public Health Medicine's recent document UK Levels of Health and the American report Healthy People 2000 are not so reluctant and identify sexually transmitted diseases and HIV as priorities and set targets for them. ${ }^{27} \mathrm{My}$ discussion therefore draws extensively on these documents.

\section{HIV and AIDS as a key area}

There is no doubt that HIV and AIDS is a major cause for concern with great potential for future harm. The World Health Organisation estimates that worldwide the total number of people infected with HIV will increase from 9 million to over 15.5 million over the next four years. By 1995, a further half million infected people are expected to be added to the 1.5 million 